ORIGINAL ARTICLE

\title{
Reality check: using newspapers, police reports, and court records to assess defensive gun use
}

\author{
J F Denton, W V Fabricius
}

Injury Prevention 2004;10:96-98. doi: 10.1136/ip.2003.003947

See end of article for authors' affiliations ......................

Correspondence to: Dr W V Fabricius, Department of Psychology, Box 871104, Arizona State University, Tempe, Arizona 85287-1104, USA; William.fabricius@ asu.edu
Objective: To identify legitimate defensive gun uses (DGUs), and provide a reality check on previous estimates of the rate of DGUs by using a novel approach based on newspaper reports and police and court records. Previous estimates have relied on self report, differ by a factor of 10 or more, and are viewed as highly controversial.

Design and setting: The reported uses of firearms in a newspaper covering roughly the Phoenix metropolitan area over almost a 3.5 month period were examined, supplemented where necessary by police and court records.

Results: Two DGUs involving killing assailants and one involving firing at an assailant were found. The three DGUs stemmed from cases of "mutual combat" or exposed bystanders to gunfire.

Conclusions: These findings cast doubt on rates of DGUs reported in an influential study by Kleck and Gertz, which predict that the police should have known about 98 DGU killings or woundings and 236 DGU firings at adversaries during the time the newspaper was surveyed. The findings reported here were closer to predictions based on the National Crime Victimization Survey, which suggest that the police should have known about eight DGU killings or woundings and 19 DGU firings at adversaries.
$\mathrm{K}$ leck and Gertz conducted a nationally representative telephone survey of defensive gun use (DGU) and estimated that each year guns are used defensively by $1.125 \%$ of civilians, which they acknowledge is higher than the DGU rate of $0.09 \%$ reported in the National Crime Victimization Survey (NCVS). ${ }^{12}$ Hemenway argued that "Many [of Kleck and Gertz's] respondents who claim to have used a gun successfully in the past year may be unconsciously improving on the truth-for example, on situations in which they were afraid, they retrieved a gun, and nothing bad happened". ${ }^{3}$ Kleck and Gertz responded that they required that reports of DGU be substantiated by answers to 19 follow up questions about the details of the incident, and that it was unlikely that many respondents could quickly invent an internally consistent story. ${ }^{4}$

\section{Kingman, Arizona-A 57-year-old man was sentenced to nine years in prison for the shooting death of a transient in a Wal-Mart store parking lot. George Ross Billingham Jr had claimed he was acting in self-defense when he shot to death Randy Ray Davis, 37, on Dec 30, 1998. But Billingham, Davis and some friends had been drinking all morning before the shooting. Prosecutor Tom Donaldson described the slaying as "a stupid drunken incident that resulted in murder". ${ }^{\prime}$}

Billingham's case would have been misclassified as DGU by Kleck and Gertz, because they "made no effort to assess either the lawfulness or morality of the respondent's defensive actions", only whether respondent confronted an adversary, used a gun in a meaningful way, thought a specific crime was being committed, and was not using the gun as part of his or her occupation. ${ }^{1}$

The controversy over the annual rate of DGUs has not been resolved, despite calls for reality checks, new methods, and better empirical data, and despite attempts to determine if differences in survey questions are responsible for divergent results. ${ }^{34-8}$ One trend has been to examine the relative rate of offensive versus defensive uses. ${ }^{9-11}$ Another has been to investigate whether DGU woundings tend not to appear in official statistics because wounded criminals do not go to emergency rooms. ${ }^{12} \mathrm{~A}$ third has been to expand on Kleck and Gertz's interview questions and ask respondents, including citizens who report having used a gun and criminals who report having been shot, to describe the circumstances to get an understanding of the types of DGUs that occur and how legitimate they may be..$^{1013} 14$

In the present study we contribute to this third trend, but we used a new method that did not rely on self reports. We searched for legitimate DGUs in a newspaper covering a major metropolitan area over almost a 3.5 month period, supplemented where necessary by police and court records. The newspaper in effect represented a daily survey of several million people for cases of DGU.

\section{METHOD}

We examined the Tribune newspaper, published in Tempe, Arizona. There were reports of gun uses in eight of the 24 cities in Maricopa County, in un-annexed land in Maricopa County, in one city in neighboring Pinal County, and in adjacent Native American tribal lands. Almost 90\% of the incidents occurred in Maricopa County, which includes the city of Phoenix. The population of Maricopa County was approximately 2806100 . Phoenix accounted for $42.59 \%$ of the county population and for $48 \%$ of the gun uses.

We collected daily newspaper reports of gun deaths for 103 days in 1998 (1 April through 31 May; 17 and 18 June; l July through 9 August). We supplemented these with reports of woundings by gun beginning on 30 April (74 days), and firings of guns on 17 and 18 June and beginning again on 11 July ( 32 days). These time periods were chosen for convenience.

The first author initially classified each instance of gun use as either self defense or one of 10 other uses: suicide,

Abbreviations: DGU, defensive gun use; NCVS, National Crime Victimization Survey 
domestic violence, accidents, road rage, arguments or fights, gang activity, unknown motive (including drive-by shootings and suspected gang activity), robbery, shooting at police officers, and use as part of occupation. If, after discussion, there was any reasonable ambiguity that an instance might be self defense, we followed up with one or more of the following: (a) a request to the police department for a copy of the police report, (b) a call to the detective in charge of the case to obtain his or her professional judgment of whether it was self defense, (c) a call to the county attorney's office to determine if the case was being prosecuted, (d) a call to the superior court to determine the outcome of the case. Calls were made by the second author who identified himself as a researcher from Arizona State University studying gun use. Rapport was easily established with detectives and office personnel, who were forthcoming with information. In a few cases, our follow up continued for several years as the case progressed. Overall, we followed up on $28(34.6 \%)$ of the individuals in $20(32.3 \%)$ of the cases.

\section{RESULTS}

We identified 43 individuals who were killed by a gun, 29 who were wounded by a gun, and nine who fired a gun. These 81 instances of gun use occurred in 62 separate cases. We followed up with the police report in six cases, the detective in 12 cases, the county attorney in four cases, and the superior court in three cases (three cases included two types of follow up and one involved three types).

\section{Cases with evidence of self defense}

We found two cases involving DGU. The first involved two off-duty security guards and an assailant, and occurred at noon on Friday 10 July at a busy gas station in a low income neighborhood in Phoenix. The newspaper report read, "[One guard] was waiting for his friend outside near the gas pumps when he argued with another man holding a gun. [The first guard] then pulled his gun, the shouting escalated, and they started shooting. When his friend heard the gunshots from inside the store, he ran out, saw the man who had apparently shot his friend, and shot him dead". ${ }^{15}$ The county attorney's office reported (4 August 2000) that no charges had been filed against either security guard, the detective reported ( 3 June 2001) that the case had been ruled "justifiable use of force", and that "it could have been a robbery attempt that started it", and the sizeable police report, which included interviews with numerous witnesses, presented the first guard's testimony that the assailant held a gun down by his own side while he pushed the guard up against a wall apparently intending to rob him, and the guard grabbed the assailant's gun and went for his own gun. Several shots were fired and one narrowly missed the second guard as he came out the door. This case accounted for one DGU death and one DGU firing, each by a security guard, and one wounding by the assailant that we did not deem self defense.

The second case involved a fight between two families. The paper reported that police had been called to these neighbors' houses nine times in the past year. On Monday 20 July at 9:30 pm, another fight broke out among at least six individuals according to neighbors, and the paper reported that according to police "within minutes, the men were hitting each other, yelling and chasing each other across the street. [One 23 year old man] hit [another] on the head with a beer bottle. Bleeding from the cut, he went into his house. [The first man] got his gun...walked into [the second man's] house and pointed the gun at [the second man's son], but was immediately shot by an unidentified man". ${ }^{16}$ After being wounded, the first man fled back toward his house, collapsed in the street, and fired 15 rounds into the house, as did another man. This case accounted for one DGU wounding, and two firings that we did not deem self defense.

\section{Case of unsubstantiated claim of self defense}

A man accidentally shot himself, reporting that he was drawing his gun "to protect himself from a man threatening him with a knife" ${ }^{17}$ We did not follow this up because we assumed no charges would be filed and there would be no witnesses.

\section{Cases of discounted claims of self defense}

There were four cases where an individual claimed DGU, but the evidence contradicted it. In two cases one man killed another claiming it was self defense. We followed one case to the county attorney and the superior court where he was convicted of first degree murder. We followed the second to the detective who reported he was charged with first degree murder.

The third involved a man who fired a shotgun at a car driving by his house at 3 am, wounding two teenagers and claiming he felt threatened. We followed this case to the superior court where he was charged with aggravated assault.

The fourth case involved a man who heard a noise in his attic one afternoon and fired several shots into his ceilings because he felt threatened. No intruder was found by police. We followed this case to the superior court where he was sentenced to probation for disorderly conduct.

\section{Cases with no evidence or claims of self defense}

There were seven suicides, three in which the person killed an intimate before turning the gun on himself, and one attempted suicide. Five other individuals were killed, one wounded, and one fired at in separate domestic cases. These included a mother killing her young daughter, a man killing his girlfriend, a man killing his wife (followed to the county attorney), a man killing his lover's husband in which the wife and another man were charged with conspiracy, a man killing another man over a woman (followed to the detective), a man wounded by his ex-girlfriend's cousins, and a man who fired at his wife during an argument. There were two accidental deaths and four accidental woundings in six separate cases.

Finally there were 17 other homicides, 16 other woundings, and three other firings (in 27 separate cases) that did not involve self defense. Six cases involved "road rage" (one was followed to the detective), eight cases involved fights or arguments (seven were followed to the police report or the detective), three involved suspected gang activity (one was followed to the police report and county attorney), six involved homicides where either the motive was unknown, drug dealing was suspected, or it was a "drive-by" shooting (three were followed to detectives), two involved robbery, and one involved shooting at a police officer.

\section{Cases of gun use as part of occupation}

Police killed six individuals in five cases, wounded one, and fired at another while on-duty, and an on-duty security guard at a hospital wounded a man who threatened him with a bottle.

\section{DISCUSSION}

Most citizens who buy a gun for protection probably envision using it to ward off sexual assaults, home invasions, or muggings. Of the two cases we found that included DGU, one involved a home invasion, but this was in the context of "mutual combat", in which a fight escalated into gun violence and both parties might claim they used their guns in self defense when in most observers' judgment both parties would be deemed blameworthy. ${ }^{1}$ The other involved a daylight mugging in a crowded area, in which the victim went for his own gun. This exposed bystanders to gunfire and resulted in the victim being shot, which casts doubt on whether the victim's gun use in this case was beneficial. 
An important limitation of our method is the likelihood of underestimating DGUs. One way this could happen is selectivity of newspaper reporting. The Uniform Crime Report indicates that there were six homicides committed by civilians with guns (including security personnel but not police) that the police deemed justifiable in Maricopa County in 1998. ${ }^{18}$ This translates to 1.7 justifiable homicides predicted during the 103 days we observed for gun deaths. The newspaper reported two such homicides (both by security guards, one off-duty and one on-duty). This suggests that underreporting of DGU killings was not a problem in our data, although the newspaper could not be expected to report all DGU woundings and firings.

A second way underestimation could occur is cases not being reported to police. One detective told us (27 August 2001), "There are cases of self defense where the defender panics and leaves the body". We were careful to check any newspaper reports of bodies found to determine if there was evidence it may have been in self defense. DGUs in which the assailant was wounded but either did not seek treatment or was able to conceal the circumstances, or in which no one was wounded could easily not come to the attention of police.

Even with these underestimation problems, our findings can serve as a reality check on the $1.125 \%$ national rate of DGU reported by Kleck and Gertz. While we should be cautious in extrapolating Kleck and Gertz' rate to one area of Arizona, in 1995 Arizona was above the national average of homes with loaded firearms, and in 1999 ranked sixth in rate of firearm deaths. ${ }^{19}$ The state has a "shall issue" concealed carry law. The rate of criminal homicides by gun (which excludes suicides, accidents, and justifiable homicides) was higher in Maricopa County than statewide in 1998, and the rates for both county and state during April through September matched the yearly rates. ${ }^{18}$

Kleck and Gertz estimated that $2.81 \%$ of DGUs are killings or woundings. (This is the hit rate of criminals shooting at their victims, which they argued is more realistic than the rate of $8.3 \%$ that their subjects reported because that would mean citizens were better marksmen than police.) Their subjects reported that $15.6 \%$ of DGUs involved firing at assailants, and $64.2 \%$ were known to the police. Kleck and Gertz's data would predict 77 cases of DGU killings or woundings in Phoenix during the 74 days in which we surveyed for homicides and woundings, 49 of which the police should know about, and 184 firings during the 32 days in which we also surveyed for firings, 118 of which police should know about. Phoenix accounted for half of gun uses, so we should expect the police to know about 98 DGU killings or woundings and 236 DGU firings.

We found only three DGUs. Two involved killing or wounding an assailant, which, if Kleck and Gertz are correct, would mean that $98 \%$ of DGU killings and woundings that the police knew about went unreported in the newspaper, and one involved firing at an assailant, which would mean that $99.6 \%$ of DGU firings that the police knew about went unreported. This casts doubt on Kleck and Gertz' rate of DGUs. Applying Kleck and Gertz' estimates to the 0.09\% DGU rate in the NCVS yields a total of eight DGU killings or woundings and 19 DGU firings at adversaries that the police should have known about. Our lower rates (two killings/ woundings, one firing) could reasonably be due to unreported cases and cases we discounted for lack of evidence, and thus they seem to corroborate the NCVS rate. Our rates may also be relevant to the related issue of whether there are more DGUs than criminal gun uses..$^{9-11}$

There may have been other DGUs that involved only drawing a gun to frighten an assailant. The newspaper does not report those, so we are unaware of the number. If that is

\section{Key points}

- Previous estimates of defensive gun use (DGU) have relied on self report, differ by a factor of 10 or more, and are viewed as highly controversial.

- We examined newspaper reports of gun use in a large metropolitan area, supplemented by police and court records.

- There were two DGUs involving killing assailants and one involving firing at an assailant.

- These DGUs stemmed from cases of "mutual combat" or exposed bystanders to gunfire.

- An influential study by Kleck and Gertz predicts that we should have found 98 DGU killings or woundings and 236 DGU firings at adversaries.

- Our findings were closer to the National Crime Victimization Survey, which predicts we should have found eight DGU killings or woundings and 19 DGU firings at adversaries.

the most prevalent type of DGU, it would imply that unloaded guns may be more effective at preventing crime than loaded guns, because we found no clear cases in which a gun was fired in self defense that did not involve "mutual combat" or firing the gun in a socially irresponsible manner so as to endanger both oneself and others.

\section{Authors' affiliations}

J F Denton, Mountain Pointe High School

W V Fabricius, Arizona State University

\section{REFERENCES}

1 Kleck G, Gertz M. Armed resistence to crime: the prevalence and nature of self-defense with a gun. Journal of Criminal Law and Criminology 1995;86:150-87.

2 National Archives of Criminal Justice Data. National Crime Victimization Survey: 1986-1991, 1992-199 (available at: http:// www.icpsr.umich.edu:80/NACJD)

3 Hemenway D. Survey research and self-defense gun use: an explanation of extreme overestimates. Journal of Criminal Law and Criminology 1997;87:1430-45.

4 Kleck G, Gertz M. The illegitimacy of one-sided speculation: getting the defensive gun use estimate down. Journal of Criminal Law and Criminology 1997;87:1446-61

5 Anonymous. Tempe Tribune 30 October 1999:A8

6 Cook PJ, Ludwig J. Defensive gun uses: new evidence from a national survey. Journal of Quantitative Criminology 1998;14:111-31.

7 Smith TW. A call for a truce in the DGU war. Journal of Criminal Law and Criminology 1997;87:1462-9.

8 McDowall D, Loftin C, Presser S. Measuring civilian defensive firearm use: a methodological experiment. Journal of Quantitative Criminology 2000;16:1-19.

9 Hemenway D, Azrael D. The relative frequency of offensive and defensive gun uses: results from a national survey. Violence and Victims 2000;15:257-72.

10 Hemenway D, Azrael D, Miller M. Gun use in the United States: results from two national surveys. Inj Prev 2000;6:263-7.

11 Kleck G. Struggling against "common sense": the pluses and minuses of gun control. The World and I 1997:287-99.

12 May J, Hemenway D, Hall A. Do criminals go to the hospital when they are shot? Inj Prev 2002;8:236-8.

13 Azrael D, Hemenway D. "In the safety of your own home": results from a national survey on gun use at home. Soc Sci Med 2000;50:285-91.

14 May JP, Hemenway D, Oen R, et al. When criminals are shot: a survey of Washington, DC, jail detainees. Med Gen Med 28 June, 2000.

15 Anonymous. Tempe Tribune 11 July 1998:A7.

16 Anonymous. Tempe Tribune 22 July 1998:A3

17 Anonymous. Tempe Tribune 28 July 1998:A3.

18 US Department of Justice, Federal Bureau of Investigation. Crime in the United States. Uniform crime reports. Washington, DC: US Department of Justice, 1998.

19 National Center for Injury Prevention and Control. Available at: http:// www.cdc.gov/brfss. 


\section{PostScript}

\section{LETTERS}

\section{Community based interventions - less than perfect?}

Thanks to Nixon et $a l^{1}$ and Moller ${ }^{2}$ for opening a dialogue on community based interventions. As learning organizations, ${ }^{3}$ we must continue to critically share evidence based and less than perfect experiments that face real world constraints. I describe here how a "successful" but imperfect start up enterprise ${ }^{4}$ enhanced that field.

From 1976-84, my co-investigators and received piecemeal funding for community based childhood poison prevention demonstration projects. (Two of the 12 resulting publications were cited in Medline.) Our Monroe County Project (MCP) intervention did not meet Nixon's inclusion protocols as a true community study with cases and controls. Ours used a quasiexperimental design with school and parent education and the media to promote purchasing and using safer products. It was associated with a 66\% decrease in hospital emergency department visits for those age $0-5$ and $60 \%$ reduction in admissions compared with two pre-intervention years and to non-experimental comparison sites. Fewer accessible household toxic products and increased observed use of safety latches in homes of children under 6 were linked to significant knowledge gain and increased calls to the poison control center.

MCP findings of significant cost-containment: \$25 dollars per project dollar spent, prompted an amendment to New York State Public Health Laws resulting in a State Regional Poison Prevention Network. This provided \$4 million per year of Medicaid funding to designated regional poison control centers. It established regulations, annual reports, and an advisory committee. ${ }^{5}$ The MCP final report guided the Centers for Disease Control and Prevention's Poison Control Advisory Group's 1996 report for enacting a US regional poison control center enhancement funding law.

Experimental creative leadership during a period of downsizing resources can lead to significant scientific contributions to intervention systems tomorrow. ${ }^{6}$

L Fisher

Safety/Management Consultant (Archivist, American Public Health Association, ICEHS Section: see related commentaries at: www.icehs.org), 97 Union Avenue, South, Delmar, NY 12054, USA; fisher166@juno.com

doi: 10.1136/ip.2004.005801

\section{References}

Nixon J, Spinks C, Turner C, et al. Community base programs to prevent poisoning children 0 15 years. Inj Prev 2004;10:43-6.

2 Moller J. Reconsidering community based interventions. Inj Prev 2004;10:2-3.

3 Senge PM. The fifth discipline. The art and practice of the learning organization. New York: Currency Doubleday, 1990.

4 Fisher L, Van Buren J, Nitzkin J, et al. Genesee region poison prevention project: phase II. Vet Hum Toxicol 1986;28:123-25 (see earlier work references).
5 Fisher L. New York State Regional Poison Control Centers Injury Control Network legislation. Vet Hum Toxicol 1986;28:545-6.

6 Quinn RE. Beyond rational management. San Francisco: Jossey-Bass Inc, 1988:86-7, 96-7 102-3

\section{Sport safety research opportunity}

A 2002 report of a United States Institute of Medicine workshop found that "no peerreviewed studies have been published to support or refute the use of helmets in soccer and no authoritative medical or sports organizations have recommended the use of helmets in soccer". ${ }^{\prime}$ However, in 2003, FIFA, soccer's international governing body, and three leading national sports bodies in the United States-US Soccer Federation, National Collegiate Athletic Association, and National Federation of State High School Associations-reversed their traditional ban on padded headgear and began to permit use by any soccer player.

Before the widespread adoption of soccer headgear makes it difficult to evaluate this latest sport injury preventive measure, ${ }^{3}$ now is a good time to start soccer headgear research projects in one or more states and countries.

A search of Medline combining "Head Protective Devices" and "Soccer" returned only four articles in English from 1966 through March 2004. Neither the Computer Retrieval of Information on Scientific Projects database of the National Institutes of Health (CRISP, accessed 6 April 2004 at www.nih.gov) nor the ProjectBank database of the National Association of Injury Control Research Centers (accessed 6 April 2004 at www.naicrc.org) listed any current or recent investigations of soccer headgear.

Sports related traumatic brain injury is an important public health problem because of the large number of cases each year, the generally young age of cases at time of injury, and the potential cumulative effects of repeated injuries. ${ }^{4}$ Nevertheless, not all new personal protective equipment is efficacious and effective.

D L Nordstrom

University of Minnesota Medical School, Department of Family Practice and Community Health 925 Delaware St, SE, Suite 220, Minneapolis, MN 55414, USA; nords110@umn.edu

\section{doi: $10.1136 /$ ip. 2004.005975}

\section{References}

1 Patlak M, Joy JE. Is soccer bad for children's heads? Summary of the IOM workshop on neuropsychological consequences of head impact in youth soccer. Washington, DC: National Academy Press, 2002:18.

2 Hiestand M. Protective soccer headgear to debut in crowning event. USA Today 2003 September $4, \mathrm{C} 2$.

3 Chalmers DJ. Injury prevention in sport: not yet part of the game? Inj Prev 2002;8(suppl IV):iv22-5.

4 Thurman DJ, Branche CM, Sniezek JE. The epidemiology of sports-related traumatic brain injuries in the United States: recent developments. $J$ Head Trauma Rehabil 1998;13:1-8.

\section{About safety and safety promotion concepts}

We were very interested in the comments of Nilsen et al on the "concept of safety" that appeared in a recent issue of Injury Prevention. ${ }^{1}$ The authors first address safety from a theoretical point of view, then from the perspective of intervention. A 1998 monograph about the concepts of "safety" and "safety promotion" are among the main sources cited by the authors. ${ }^{2}$ This monograph, an initiative of the World Health Organization (WHO), was prepared jointly by two WHO sponsored collaborating centers (Québec WHO Collaborating Center for Safety Promotion and Injury Prevention and WHO Collaborating Center on Community Safety Promotion, Karolinska Institute), and is available in .pdf format on the Institut national de santé publique du Québec's website, in English, at http://www.inspq. qc.ca/pdf/publications/150_SecurityPromotion. pdf and in French at http://www.inspq.qc.ca/ pdf/publications/149 SecuritePromotion.pdf. This document deals with the concepts of safety and of "safety promotion". It offers a definition of safety promotion, and two distinct and complementary processes to promote its implementation: the problem based process and the setting based process. These two processes represent a "safety promotion approach". An example illustrating this approach is presented at the end of the monograph. Over the past few years, two articles were published about this monograph in scientific journals. ${ }^{34}$

P Maurice, M Lavoie

Québec WHO Collaborating Center for Safety Promotion and Injury Prevention, 2400 d'Estimauville, Beauport, Quebec, Canada G1E 7G9

Correspondence to: Pierre Maurice; pierre.maurice@ ssss.gouv.qc.ca

doi: 10.1136/ip.2004.006080

\section{References}

1 Nilsen P, Hudson DS, Kullberg A, et al. Making sense of safety. Inj Prev 2004;10:71-3.

2 World Health Organization. Safety and safety promotion: conceptual and operational aspects. Québec: WHO, 1998:1-20.

3 Maurice P, Lavoie M, Chapdelaine A, et al. Safety and safety promotion: conceptual and operational aspects. Chronic Dis Can 1997;18:179-86.

4 Maurice P, Lavoie M, Laflamme L, et al. Safety and safety promotion: definitions for operational developments. Injury Control and Safety Promotion 2001;8:237-40.

\section{BOOK REVIEWS} World Report on Road Traffic Injury Prevention.

M Peden, R Scurfield, D Sleet, D Mohan, A A Hyder, E Jarawan, C Mathers. (Swiss Fr 30/US \$27; in developing countries Swiss $\mathrm{Fr} 15$.) Geneva: World Health Organization, 2004. ISBN 92-4-156260-9.

This impressive report aims to raise awareness about the extent of road traffic collisions 
globally, to draw attention to their preventability, and to call for a coordinated partnership approach to addressing the problem. In its five chapters it gives in turn a comprehensive catalogue of the fundamentals of road safety, the impact of road trauma across the world, the key factors contributing to crashes and consequential injuries, successful interventions which have been applied (mainly in high income countries) to reduce the problem, with the final chapter containing conclusions and recommendations.

The report points out that over 3000 lives are lost daily to road traffic collisions. While a decrease in road deaths of some $30 \%$ is forecast in high income countries (HICs), projected trends in low and middle income countries (LMICs) foreshadow a huge increase in road crash mortality between 2000 and 2020. Hence the report quickly identifies that the priority globally should be effective interventions in LMICs.

In chapter 1 on fundamentals there is a recognition that "technology transfer from high-income to low-income countries needs to fit local conditions and should address research-based local needs". However chapter 4 on interventions, and to some extent the recommendations, seem to lose sight of this message and dwell upon technologies which have been evaluated only in HICs, as well as new strategies which could be quite unsuitable for LMICs. There is an impression that the HICs have got it right in terms of managing road trauma, and that LMICs should follow the interventions and principles developed in HICs (albeit adapted to local conditions and constraints).

There are, however, at least two key areas where HICs did not get it right during the last 50-60 years when road transport became both more available and cheaper and cheaper for the general population and industry. The first is that we have been reluctant to manage exposure to risk. As noted in chapter 4, exposure management is the least used of all road safety intervention strategies. This is because, in HICs, there has been a fundamental belief in the high value of personal motorised mobility, covering distance in the minimum time consistent with comfort. Thus constraints on exposure, and speed, have been given low priority compared to interventions which collectively could be seen as "patching up" the factors causing the crash and injury consequences of exposure and the kinetic energy derived from speed. It may not be too late for LMICs to challenge the unbridled growth in motorised transport, or at least to give much higher priority to managing exposure through land use policies and transport strategies in general (for example, separating road transport modes operating with disparate speeds and masses; discouraging unnecessary trips; and encouraging the use of safer and non-road travel modes). HICs have begun to challenge their own values in this area, as the costs of road trauma are valued at much higher levels than in the past. HICs should encourage LMICs not to make the same mistakes, by fully recognising the real costs of road trauma against the intangible values of some elements of motorised transport, especially personal mobility.

The second key area where HICs did not get it right is that investment in road safety research and development has been relatively small in comparison with other types of health loss (infectious diseases, etc). The report iden- tifies that funding for interventions, even in the HICs most active in road safety, has been scarce. Road safety efforts in HICs have failed to match the severity of the problem and continue to do so. There are good historical reasons why this was the case, including belief in the accidental nature of the problem and fatalistic acceptance of its inevitability, but the situation has changed in HICs. LMICs need to really believe that the problem is preventable, that it is worth the substantial investment in research and research based action programs, and that successful interventions from HICs cannot simply be transferred to each LMIC without research and development in local conditions. It needs to be recognized that this investment in prevention will need to be substantial, but it is at least as justified as other health program investments because of the enormous and increasing costs of road trauma in each LMIC.

The report highlights the road safety model of Victoria, Australia as a good example of a cooperative partnership which led to substantial road safety benefits. There were attempts to transfer the Victorian model of strong traffic law enforcement supported by high profile mass media publicity to KwaZulu-Natal (KZN) province in South Africa during the late 1990s. There was little effort to adapt the successful Victorian interventions to South African conditions and constraints. Perhaps the advisers (of which I was one) misinterpreted KZN as ready for an HIC-type road safety program. The initial years of Project Victoria (later renamed "Asiphephe") in KZN saw a $31 \%$ reduction in road trauma (deaths and injuries) between 1996 and 1998, but by 2001 road trauma had returned to 1995 levels. Perhaps one of the reasons the government and population of KZN lost their commitment to Project Victoria (J Bodinnar, personal communication) was that they saw it as essentially an HIC approach, not adapted or suitable for local conditions or beliefs.

This is not to suggest that partnerships of public and private agencies are not a key factor in coordinating the range of organisations which would have responsibilities and resources for road safety in a typical LMIC. The failure in KZN was essentially due to the lack of investment in research and development in local conditions to provide the background for the transfer of principles, and perhaps successful interventions, from an HIC. Partnerships, and shared responsibility for the road safety "system", are key elements of Sweden's "Vision Zero" strategy which is being seriously considered in HICs to guide their future directions. Perhaps many LMICs would find the ultimate goal of zero road trauma intimidatory and unrealistic given their current resources. The target should not distract attention in either LMICs or HICs away from the systematic and cooperative aspects of the Swedish strategy.

Notwithstanding these concerns about the LMICs making the same mistakes as the HICs if they follow them uncritically, the report is an excellent overview of what has been effective in reducing road trauma in HICs. The report also provides the basis for fundamental strategic thinking in the field, armed with which many LMICs may be able to reduce more quickly or even avoid their burgeoning road trauma problems.

M Cameron Melbourne, Australia; Max.Cameron@general.monash.edu.au

\section{Drive On! A Social History of the Motor Car.}

L J K Setright. (Pp 405; £25 hardback.) London: Granta Books. ISBN 1-86207-628-6.

This is an entertaining, idiosyncratic history of the motor car written by a long time motoring writer. It looks at the way cars changed history - examining change first of all by decade, then by associated issues such as the effect on cities and where to stop, then according to particular technical facets from hand cranking to computer control. For those interested in injury prevention, the most significant part of the book is that a history of the motor car can be written without a single indexed reference to seat belts, airbags, safety, alcohol, or traffic lights, slighting and dismissive references to seminal work such as Nader's Unsafe at Any Speed, which is referred to as a "snide red rag" of a book, and no understanding of the huge social and economic cost associated with road death and trauma.

I Scott

ianscott@irtual.net.au

Twenty Years As A Police Surgeon. John Birrell. (Pp 104; Aus $\$ 29.95$ paperback.) Brolga Publishing Pty Ltd, 2004 (P O Box 959, Ringwood, Victoria 3134; email: markzocchi@ brolgapublishing.co.au). ISBN 1-920785-24-8.

This is a memoir that reflects one of the great stories in injury prevention-the $70 \%$ fall in road traffic deaths in Victoria. Dr Birrell was at the centre of developments in road traffic injury reduction in Victoria, from the early days in the late 1950s to the period when it had become clear that the modern epidemic of road injury could be contained and the large reductions had begun. It deals with the efforts to get seatbelts installed and used, the enormous struggle to overcome the conspiracy of silence and to get road death taken seriously and, above all, the battle to contain the effect of alcohol as a component in road trauma. Although firmly located in Australia, the book is noted here because it is one of very few to focus on the how of injury prevention, on how interest was fostered and on how interventions and polices were developed, checked, and changed until the death rates came down.

I Scott

ianscott@virtual.net.au

\section{CORRECTION}

doi: 10.1136/ip.2003.003947corr l

Reality check: using newspapers, police report, and court records to assess defensive gun use

The above paper was published in the April issue (Inj Prev 2004;10:96-98) and the authors would like to correct some minor errors. In the second paragraph of the discussion the authors stated "The newspaper reported two such homicides (both by security guards, one off-duty and the other on-duty)"; this should have read "...one such homicide...". In the abstract and key points where it states that there were two DGUs [defensive gun uses] involving killing assailants it should read "Two DGUs involving killing or wounding assailants". 